\title{
Remote ischemic preconditioning preserves Connexin 43 phosphorylation in the rat heart in vivo
}

Timo Brandenburger ${ }^{1}$, Ragnar Huhn ${ }^{1 *}$, Andreas Galas ${ }^{1}$, Benedikt H Pannen ${ }^{1}$, Verena Keitel ${ }^{2}$, Franziska Barthel ${ }^{1}$, Inge Bauer ${ }^{1}$ and André Heinen ${ }^{1,3}$

\begin{abstract}
Background: Remote ischemic preconditioning (RIPC) protects the heart from ischemia and reperfusion (I/R) injury The underlying molecular mechanisms are unclear. It has been demonstrated that Connexin $43(C \times 43)$ is critically involved in cardioprotective interventions including classical ischemic preconditioning. In the present study we investigated the influence of RIPC on the expression patterns of Cx43 after I/R in the rat heart in vivo.
\end{abstract}

Methods: Male Wistar rats were subjected to 35 min regional myocardial ischemia followed by $2 \mathrm{~h}$ reperfusion with or without 4 cycles of 5 minutes bilateral hind limb ischemia and reperfusion (RIPC), to RIPC without ischemia or underwent no intervention (Sham). Infarct size was measured by TTC staining. The myocardium was divided into area at risk (AAR) and area not at risk (non AAR). Expression of Cx43-mRNA and protein was analyzed by qPCR and Western Blot analysis, respectively. Localization of Cx43 was visualized by confocal immunofluorescence staining.

Results: RIPC reduced the infarct size (I/R: $73 \pm 5 \%$ vs. RIPC I/R: $34 \pm 14 \%, p<0.05)$. Expression of CX43 mRNA did not differ between groups. I/R caused a strong decrease of relative $\mathrm{C} \times 43$ protein expression in the AAR that was partly abolished by RIPC. Furthermore, RIPC decreased the level of ischemia-induced dephosphorylation of Cx43. Confocal immunofluorescence staining showed that I/R caused a loss of the CX43 signal at the intercalated discs, while the Cx43 signal at the intercalated discs was partly sustained after RIPC.

Conclusion: Preservation of $\mathrm{C} \times 43$ protein expression and phosphorylation after RIPC might protect the rat heart in vivo.

Keywords: Cardioprotection, Connexin 43 (Cx43), Remote ischemic preconditioning (RIPC)

\section{Background}

In 1993 Przyklenk and colleagues published the observation that regional mycardial ischemia can protect the remote myocardial tissue from subsequent ischemia [1]. This concept - termed remote ischemic preconditioning (RIPC) - has later been extended by studies showing that a protective myocardial effect could also be achieved by short intervals of limb ischemia [2], a fact which makes RIPC easily applicable and clinically interesting. Recently, the potential clinical impact of RIPC has been demonstrated in two studies by Botker et al. [3] and Thielmann et al. [4].

\footnotetext{
* Correspondence: ragnar.huhn@med.uni-duesseldorf.de

'Department of Anesthesiology, University Hospital Duesseldorf, Moorenstr. 5, 40225 Düsseldorf, Germany

Full list of author information is available at the end of the article
}

Botker and colleagues demonstrated that remote ischemic conditioning induced by intermittend periods of arm ischemia before angioplasty increased myocardial salvage in patients suffering from acute myocardial infarction [3]. The clinical investigation by Thielmann and colleagues showed that RIPC by transient ischemia of the left upper arm can provide perioperative myocardial protection and improve the prognosis of patients undergoing elective coronary artery bypass surgery [4]. However, the exact molecular mechanisms underlying RIPC are unknown and elucidation of these mechanisms is of great clinical importance. One of the molecules involved in the events following cardiac ischemic preconditioning (IPC) is $\mathrm{Cx} 43$ [5]. Cx43 is the main gap junction component of the heart ventricle and is mainly located at the intercalated discs. It 
contributes to mechanical stability as well as electrical and chemical coupling of cardiomyocytes [6]. After prolonged ischemia, Cx43 is dephosphorylated [7] which leads to the opening of Cx43-formed hemichannels [8] and a translocation of $\mathrm{Cx} 43$ from the gap junctions towards the plasma membrane [9] or to an intracellular pool [10]. IPC attenuates this ischemia-induced dephosphorylation of sarcolemmal Cx43 in rat hearts [11]. Furthermore, heterozygous deficiency of $\mathrm{Cx} 43$ in mice leads to a loss of the cardioprotection by IPC $[12,13]$.

There is no study showing an impact of RIPC on the Cx43 phosphorylation status or $\mathrm{Cx} 43$ protein distribution in the context of cardiac I/R. We hypothesised that RIPC preserves $\mathrm{Cx} 43$ phosphorylation and therefore analyzed the expression pattern of $\mathrm{Cx} 43$ in a rat model of RIPC followed by I/R.

\section{Methods}

Animal experiments

Animal experiments were performed in accordance with the German legislation on protection of animals and the National Institutes of Health Guide for the Care and Use of Laboratory Animals (NIH Publication No. 85-23, revised 1996) as described previously [14]. Animals had free access to food and water at any time. Rats were anesthetized by an intraperitoneal injection of pentobarbital $(100 \mathrm{mg} / \mathrm{kg}$ body weight). Before surgery, adequate depth of anesthesia was verified by the absence of reaction after pain stimuli. After tracheal intubation, the right jugular vein was cannulated for saline and drug infusion, and the left carotid artery was cannulated for measurement of aortic pressure. A lateral left-sided thoracotomy was performed and a suture (5-0) was looped around a major branch of the left coronary artery. All animals were left untreated for 10 min before the start of the respective experimental protocol.

\section{Experimental in vivo protocol}

Myocardial ischemia and RIPC were performed as described before. [14]. In brief, rats were randomly assigned to one of the following groups (Figure 1, $\mathrm{n}=6$ / group): 1. Sham: Animals underwent a time matched sham procedure without intervention. 2. Remote ischemic preconditioning only (RIPC): 4 cycles of 5 minutes bilateral hind limb ischemia/5 minutes reperfusion without I/R. 3. Ischemia/ Reperfuion (I/R): 35 minutes of regional myocardial ischemia by occlusion of a branch of the left coronary artery (LAD) followed by 120 minutes of reperfusion. 4 . Remote ischemic preconditioning followed by ischemia/ reperfusion $(\mathrm{RIPC}+\mathrm{I} / \mathrm{R})$. At the end of the experiment, the branch of the LAD was re-occluded and $5 \mathrm{ml}$ Evans blue solution were injected intravenously. By this method, the area non at risk (non AAR) is stained blue while the area at risk (AAR) remains unstained. Subsequently, the hearts were removed, and the myocardium was separated in $A A R$ and nonAAR. Both tissue fractions were snap frozen in liquid nitrogen and stored at $-80^{\circ} \mathrm{C}$ until further analysis.

In a second series, the same experimental protocol was used to assess infarct size in I/R and RIPC $+\mathrm{I} / \mathrm{R}$ animals ( $n=6$ / group).

\section{Infarct size measurement}

Infarct size measurement was performed as described previously [15]. In brief, after $120 \mathrm{~min}$ of reperfusion, the hearts were excised with the occluding suture left in place and then mounted on a modified Langendorff apparatus for perfusion with ice cold normal saline. After $5 \mathrm{~min}$ of perfusion, the coronary artery was re-occluded and the heart perfused with $0.2 \%$ Evans blue in normal saline for $10 \mathrm{~min}$. Intravascular Evans blue was washed out by perfusion with normal saline for $10 \mathrm{~min}$. This treatment identified the area at risk as unstained. The heart was cut into $2 \mathrm{~mm}$ thick transverse slices. The slices were stained with $0.75 \%$ triphenyltetrazolium chloride solution for $15 \mathrm{~min}$ at $37^{\circ} \mathrm{C}$ and fixed in $4 \%$ formalin solution for $24 \mathrm{~h}$ at room temperature. The area at risk and the infarcted area were determined by planimetry using SigmaScan Pro $5^{\circ}$ computer software (SPSS Science Software, Chicago, IL).

\section{RNA isolation}

Total RNA of rat hearts was isolated using Trizol reagent (Invitrogen, Carlsbad, USA) according to the manufacturer's

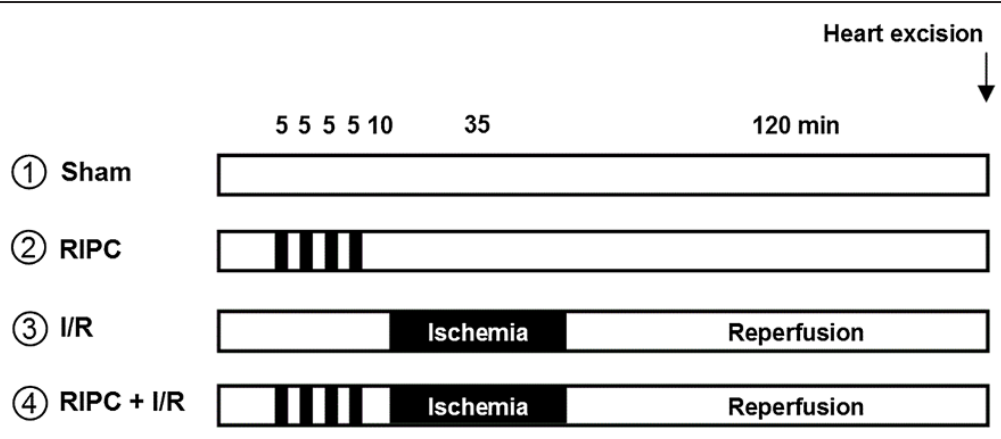

Figure 1 Experimental in vivo protocol. RIPC = remote ischemic preconditioning, I/R ischemia and reperfusion, $\mathrm{n}=6 / \mathrm{group}$. 
protocol. RNA quantity was determined by UV spectrophotometry (Nanodrop, Thermo Scientific, USA) and RNA integrity was verified by agarose gel electrophoresis using $2.5 \mu \mathrm{g}$ of total RNA per lane.

\section{RNA-qPCR assay}

$1 \mu \mathrm{g}$ of total RNA was reverse transcribed using the High Capacity RNA-to-cDNA Master Mix according to the manufacturer's protocol (Applied Biosystems). The qPCR assay for Cx43 was generated by TIB MOLBIOL (Berlin, Germany). The sequence of the forward primer is 5'-AGGAGTTCCACCAACTTTGGC-3', reverse primer 5' -TGGAGTAGGCTTGGACCTTGTC-3' and 5' -FMAAGCTTCCCCAAGGCACTCCAGTC-BBQ-3' for the reporter probe. GAPDH (Assay ID: Rn_01775763, Applied Biosystems) was used for normalization. qPCR conditions: $50^{\circ} \mathrm{C}$ for $2 \mathrm{~min}, 95^{\circ} \mathrm{C}$ for $10 \mathrm{~min}, 40$ cycles of $95^{\circ} \mathrm{C}$ for $15 \mathrm{~s}, 60^{\circ} \mathrm{C}$ for $60 \mathrm{~s}$ on an Applied Biosystems $7300 \mathrm{HT}$ thermocycler (Applied Biosystems). All samples were run in triplicates and PCR was repeated twice. Relative expression was estimated using the $\Delta \Delta \mathrm{Cq}$-method [16] and the relative expression software tool [17].

\section{Subcellular fractionation}

The membrane fraction of proteins was obtained by differential centrifugation. The frozen heart tissue was pulverized and dissolved in lysis buffer containing $5 \mathrm{mM}$ Tris base, $2 \mathrm{mM}$ EGTA, $50 \mathrm{mM} \mathrm{NaF}$ and $2 \mathrm{mM} \mathrm{Na} \mathrm{VO}_{4}$ (as phosphatase inhibitors), a freshly added protease inhibitor mix (Complete; Roche) and 5 mM DTT. The solution was vigorously homogenized on ice (Homogenizor; IKA, Staufen, Germany) and then centrifuged at $600 \mathrm{~g}$ at $4^{\circ} \mathrm{C}$ for $10 \mathrm{~min}$. The supernatant was centrifuged at $15.000 \mathrm{~g}$ at $4^{\circ} \mathrm{C}$ for 15 minutes, followed by ultracentrifugation at $100.000 \mathrm{~g}$ at $4^{\circ} \mathrm{C}$ for $1 \mathrm{~h}$. The pellet was resuspended with lysis buffer containing 1\% Triton and incubated on ice for $60 \mathrm{~min}$. The supernatant containing the membrane fraction was transferred to a new tube for further analysis.

\section{Western blotting}

Protein concentration was measured by the Lowry method and equal amounts of protein were mixed with loading buffer (1:1) containing Tris- $\mathrm{HCl}$, glycerol, sodium dodecyl sulfate and bromphenol blue. Samples were mixed 1:10 with 2 - $\beta$-mercaptoethanol and incubated at $95^{\circ} \mathrm{C}$ for $5 \mathrm{~min}$, and loaded on a 10\% SDS-polyacrylamide gel. The proteins were separated by electrophoresis and transferred onto a polyvinylidene difluoride membrane by tank blotting (100 V, $1 \mathrm{~h}$ ). Unspecific binding of the antibody was blocked by incubation with $5 \%$ nonfat dry milk in Tris-buffered saline containing Tween 20 for $2 \mathrm{~h}$. The membrane was incubated overnight at $4^{\circ} \mathrm{C}$ with the primary antibody (Cx43, ab11370, abcam, Cambridge, UK,
1:1000). After washing in fresh, cold Tris-buffered saline containing Tween, the blot was incubated with the appropriate horseradish peroxidase conjugated secondary antibody for $2 \mathrm{~h}$ at room temperature. Immunoreactive bands were visualized by chemiluminescence detected with a high-resolution camera using an enhanced chemiluminescence system (Santa Cruz Biotechnology, Santa Cruz, Calif). The signal intensities of the corresponding bands in Western blot were measured using GelScan 6.0 software (Decon Science Tec, Frankfurt, Germany). Equal loading of protein was verified by probing the membrane with $\mathrm{Na}^{+} / \mathrm{K}^{+}$-ATPase antibody (Abcam ab 7671, Cambridge, UK, 1:5000).

\section{Immunofluorescence staining and confocal laser scanning} microscopy

Frozen heart tissue was cut into $8 \mu \mathrm{m}$-thick sections, fixed in $4 \%$ paraformaldehyde for $10 \mathrm{~min}$ at room temperature and washed with phosphate buffered saline. Subsequently, cryosections were blocked and permeabilized for $1 \mathrm{~h}$ with blocking buffer containing $10 \%$ normal goat serum and $0.2 \%$ saponine in phosphate buffered saline.

Subsequently, cryosections were incubated with the primary Cx43 antibody (Abcam ab11370, Cambridge, UK, $1: 1000)$ at $4^{\circ} \mathrm{C}$ overnight. A secondary antibody (Cy3-conjugated goat-anti-rabbit, Jackson Immuno Research Laboratories, USA, Code 111-165-144, 1:400) was applied for $4 \mathrm{~h}$ at room temperature. Glass slides were washed with phosphate buffered saline and mounted to coverslips with mounting medium (ProLong Gold antifade reagent with DAPI; Invitrogen). Immunostained samples were analyzed using a Zeiss LSM510META confocal microscope.

\section{Statistical analyis}

All values were tested for normal distribution and are expressed as mean $\pm \mathrm{SD}$. Hemodynamic data were analyzed by two-way analysis of variance (ANOVA) followed by Tukey's post hoc test (Sigmastat Software, version 3.5). After failing testing for normal distribution, a Kruskal-Wallis test followed by Dunn's posthoc testing was performed for analyzing Western Blot data of Cx43 protein expression. $\mathrm{P}<0.05$ was used to indicate statistical significance.

\section{Results}

\section{Hemodynamic variables}

No significant differences in hemodynamic baseline variables were observed between treatment groups. Heart rate was significantly lower in the $I / R$ and the $R I P C+I / R$ group after 120 minutes of reperfusion compared to baseline values and to Sham animals. Blood pressure was significantly lower in $I / R$ and $R I P C+I / R$ animals 
after 120 minutes of reperfusion compared to baseline values and was lower in the I/R group compared to Sham animals (details in Additional file 1: Table S1 and S2).

\section{Infarct size measurement}

In the I/R group, infarct size was $72.6( \pm 5) \%$ (Figure 2). Infarct size was reduced by RIPC to $34.1( \pm 14) \%(\mathrm{p}<0.01$, $n=6$ ). Furthermore, there was no difference in the area at risk between groups (data not shown), therefore the differences in infarct sizes were not caused by differences in area at risk.

\section{Cx43 mRNA expression}

Realtime quantitative PCR was performed to analyze the expression of $\mathrm{Cx} 43$ mRNA. There were no differences in the expression level of Cx43 mRNA between the groups (Figure 3).

\section{Cx43 protein expression}

Cx43 protein expression was analyzed by Western Blotting using the membrane fractions of heart tissue. A Cx43 antibody detecting both phosphorylated as well as unphosphorylated $\mathrm{Cx} 43$ was applied.

Total $\mathrm{Cx} 43$ protein expression was significantly reduced in the AAR of hearts subjected to I/R hearts compared to Sham hearts (relative expression versus $\mathrm{Na}^{+} / \mathrm{K}^{+}$-ATPase: 0.73 for $I / R$ vs. 2.65 for Sham, $\mathrm{p}<0.05$ ) (Figure $4 \mathrm{~b}$ ). Interestingly, this decrease is not only observed in the AAR but also in the non AAR of $I / R$ hearts (relative expression 1.05 versus $\mathrm{Na}^{+} / \mathrm{K}^{+}$-ATPase, $\mathrm{p}<0.05$ ). In contrast, there is no significant decrease in $\mathrm{Cx} 43$ protein expression in the AAR of hearts pretreated with RIPC (RIPC $+\mathrm{I} / \mathrm{R}$, relative expression 1.43).

$\mathrm{C} \times 43$ can be phosphorylated at several sites including $\mathrm{Ser}^{365}, \mathrm{Ser}^{325}, \mathrm{Ser}^{328}$ and $\mathrm{Ser}^{330}$ and phosphorylation of these sites is known to affect SDS/PAGE migration [18]. The fastest migrating band is termed $\mathrm{P} 0$, it is the dephosphorylated form of $\mathrm{Cx} 43$. For analyzing the phosphorylation status of $\mathrm{Cx} 43$, we determined the ratio of phosphorylated to total $\mathrm{Cx} 43$ protein content. Phosphorylation of Cx43 was significantly decreased in the AAR of $\mathrm{I} / \mathrm{R}$ hearts (Phosphorylated Cx43/total $\mathrm{Cx} 43=0.22)$ in comparison to Sham $(0.71)$ as well as in comparison to the AAR of RIPC $+\mathrm{I} / \mathrm{R}$ hearts $(0.59)$ (Figure 4c). Thus, RIPC prevents the I/R-induced dephosphorylation of $\mathrm{Cx} 43$.

\section{Immunofluorescence staining of $\mathrm{Cx} 43$}

To analyze the distribution of Cx43, heart tissue was labelled with a Cx43 antibody. In Sham animals, the strongest $\mathrm{Cx} 43$ signal was detected at the intercalated discs (Figure 5A). In contrast, in the AAR of I/R sections the Cx43 signal at the intercalated discs was lost and Cx43 could to a lesser degree be detected

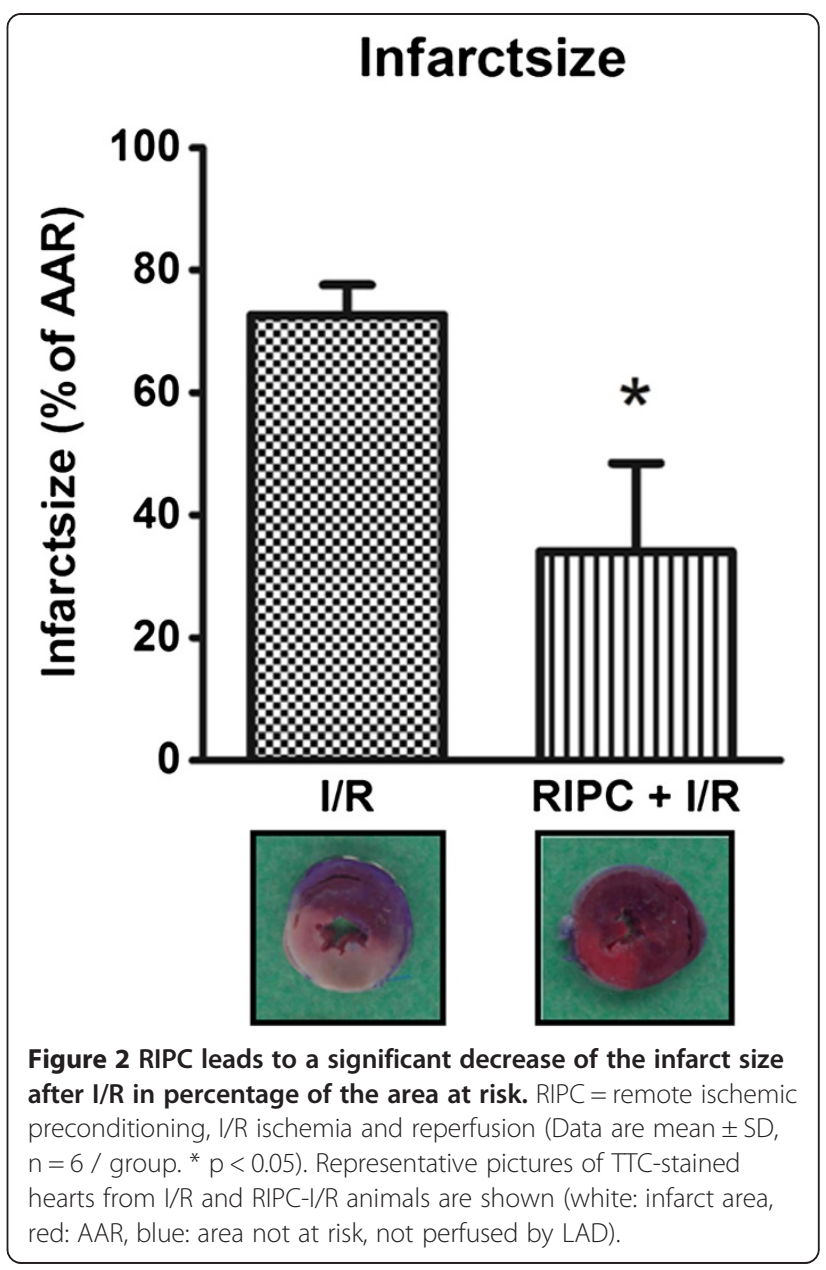

in the cardiomyocyte plasma membrane (Figure 5B). In the AAR of heart sections treated with RIPC before I/R, some of the Cx43 protein content at the intercalated discs was preserved and to a lesser amount lateralized to the plasma membrane (Figure 5C).

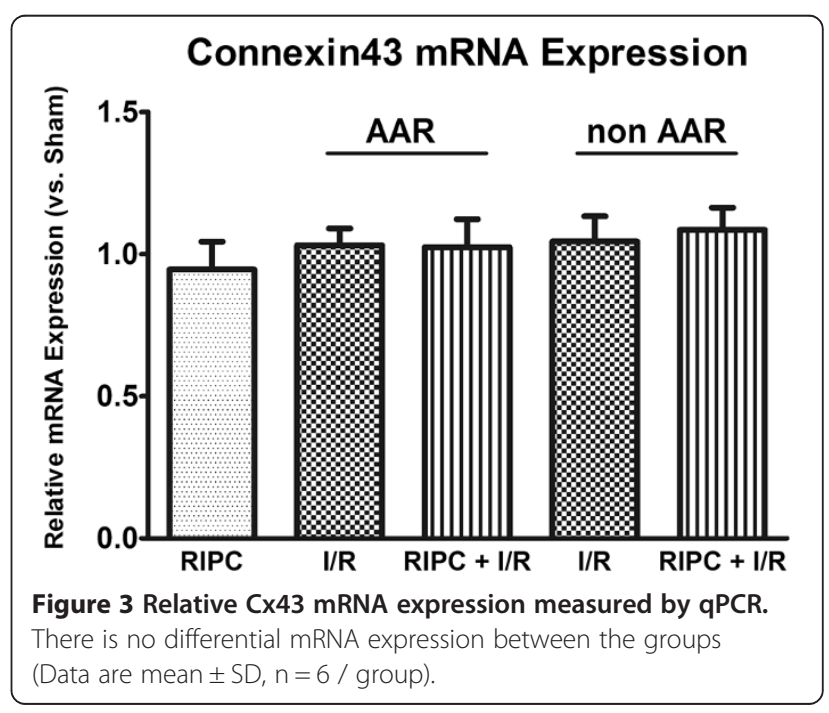



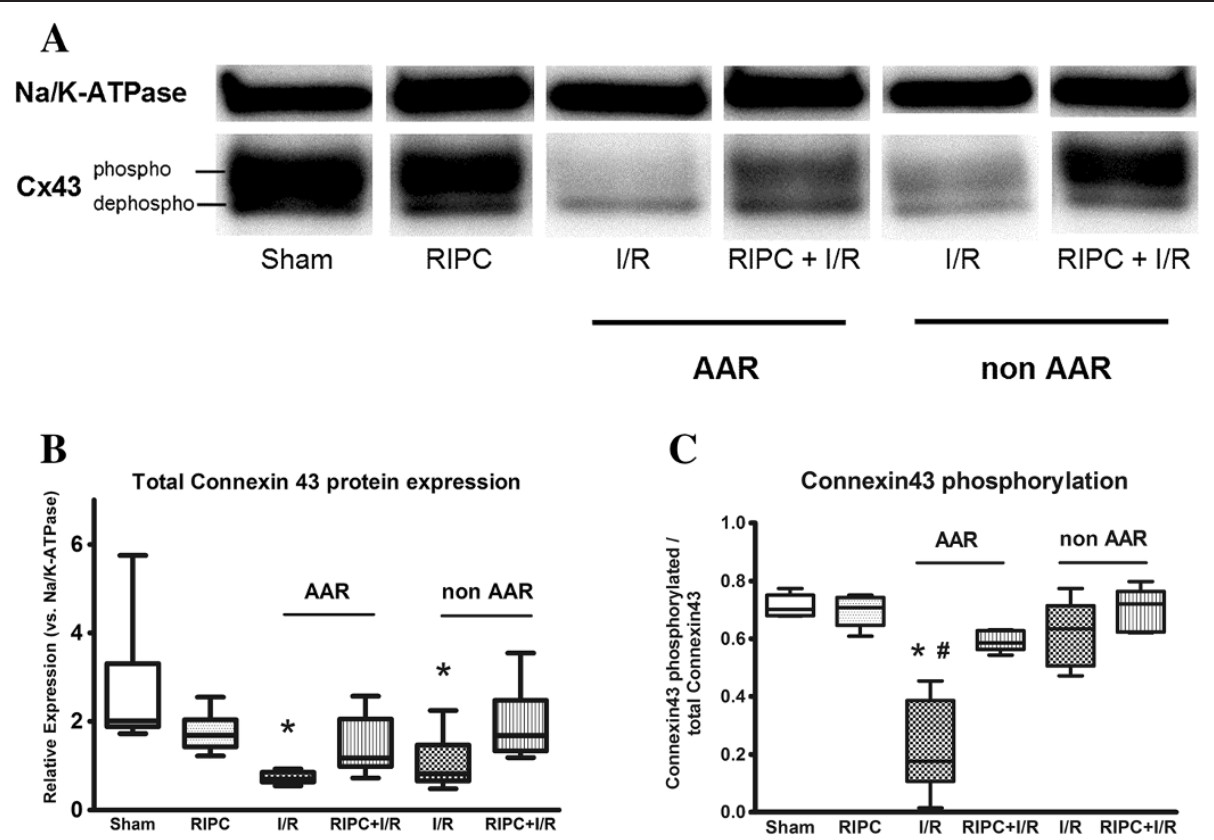

Figure 4 Western Blot analysis of Cx43 protein expression. (A) Exemplary original blot showing the expression of $\mathrm{Cx} 43$ and $\mathrm{Na}^{+} / \mathrm{K}^{+}$-ATPase. The upper $\mathrm{Cx} 43$ band represents the expression of phosphorylated $\mathrm{Cx} 43$, while the lower band corresponds to dephosphorylated Cx43. (B) Relative expression of total $\mathrm{Cx} 43$ protein vs. $\mathrm{Na}^{+} / \mathrm{K}^{+}$-ATPase. Cx43 expression is significantly lower in the AAR of I/R hearts compared to Sham. (C) Analysis of phosphorylated vs. dephosphorylated CX43. The degree of dephosphorylated Cx43 is higher in the AAR of I/R hearts compared to Sham and RIPC + I/R hearts. RIPC = remote ischemic preconditioning, I/R = ischemia and reperfusion, (Data are median, min to $\max , \mathrm{n}=6 /$ group. ${ }^{*} \mathrm{p}<0.05$ ).

\section{Discussion}

In this study we show that RIPC 1) attenuates the ischemia-induced dephosphorylation of $\mathrm{Cx} 43,2)$ partially prevents the lateralization of $\mathrm{Cx} 43$ from the intercalated discs to the plasma membrane, and 3) reduces the degree of $\mathrm{Cx} 43$ degradation.

Though being first described 20 years ago [1], the exact molecular mechanisms underlying RIPC are unknown. Humoral factors, a neural pathways or microRNAs [19] have been proposed for mediating the cardioprotective effects following RIPC (reviewed in [20]). The molecular events following IPC, where myocardial I/R is induced by direct transient ligation of a coronary artery, are better characterized than the mechanisms underlying RIPC, where the ischemic event occurs in an organ distinct from the heart. While some studies suggest that the molecular events mediating RIPC are similar to events following IPC [21], a study of our group has shown that RIPC exhibits a different signalling pattern compared to IPC [14]. One protein that has been extensively studied in the context of IPC is Cx43. Cx43 is an integral membrane protein that is mainly localized at the sarcolemma of ventricular cardiomyocytes where six connexin molecules assemble into a connexon or hemichannel [22]. The protein can be phosphorylated at numerous Serin sites including $\mathrm{Ser}^{325}, \mathrm{Ser}^{328}, \mathrm{Ser}^{330}, \mathrm{Ser}^{365}$ and $\mathrm{Ser}^{262}$. Phosphorylation
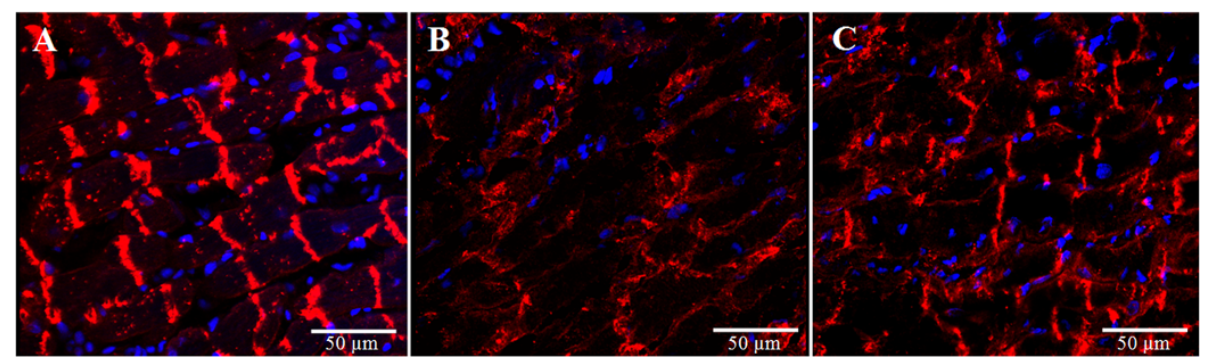

Figure 5 Immunofluorescence staining of Cx43 in rat hearts. (A) Cx43 is mainly located at the intercalated discs of Sham hearts. (B) In I/R hearts, the Cx43 signal at the intercalated discs is lost and Cx43 is partly lateralized to the plasma membrane. (C) RIPC leads to a partial preservation of $\mathrm{C} \times 43$ at the intercalated discs after I/R. RIPC = remote ischemic preconditioning, $1 / R=$ ischemia and reperfusion. 
(or dephosphorylation respectively) is able to induce conformational changes within the $\mathrm{Cx} 43$ molecule [23] and the phosphorylation status of $\mathrm{Cx} 43$ is related to stress response and resistance of cells to injury [24]. $\mathrm{Cx} 43$ is a target protein of several protein kinases such as protein kinase A (PKA), protein kinase $C$ (PKC), protein kinase $G$ (PKG), protein tyrosine kinases and mitogen activated protein kinases (MAP kinases) [7].

\section{Myocardial ischemia, Cx43 and cardioprotection}

It has been shown that prolonged myocardial ischemia leads to a dephosphorylation of Cx43 [25]. Our data confirm this finding. In addition, myocardial ischemia causes a re-distribution of $\mathrm{Cx} 43$ to the lateral plasma membrane. Besides this lateralization, some of the Cx43 is degraded following prolonged cardiac ischemia [26].

In our experimental model, we could reproduce both findings, lateralization and degradation of Cx43 caused by myocardial I/R. These effects of myocardial $I / R$ on Cx43 dephosphorylation, lateralization and degradation can be modulated by cardioprotective interventions including IPC. Ischemia-induced dephosphorylation of sarcolemmal $\mathrm{Cx} 43$ is attenuated by IPC in rat hearts [11], which may be related to an enhanced association of Cx43 with kinases such as PKC and p38 mitogen-activated protein kinases [27]. Furthermore, heterozygous deficiency of Cx43 in mice leads to a loss of cardioprotection by IPC $[12,13]$. There are no data dealing with the role of $\mathrm{Cx} 43$ in RIPC. We therefore analyzed a possible impact of RIPC on both Cx43 mRNA and protein expression levels and cellular distribution in the context of cardiac $I / R$ in male Wistar rats. Our data demonstrate that RIPC protects against the I/R-induced dephosphorylation of Cx43. RIPC also attenuates the I/R-induced degradation and lateralization of Cx43. Dephosphorylation of Cx43 increases the permeability of gap junctions and thereby contributes to the propagation of $I / R$ injury [28], as during reperfusion following prolonged ischemia a death factor (such as sodium ions) is able of spreading more easily between cells [29]. An uncoupling of this propagation as a consequence of a preservation of phosphorylation is potentially cardioprotective. Therefore, presevation of $\mathrm{Cx} 43$ phosphorylation and protein content as shown in our study could contribute to the protective effects of RIPC. We furthermore show that the preservation of Cx43 protein is not associated with changes in $\mathrm{Cx} 43$ mRNA expression. This is in line with other studies showing that changes in $\mathrm{Cx} 43$ protein content and phosphorylation following hypoxia are not accompanied by changes in Cx43 mRNA expression [30].

In IPC, the preserved phosphorylation of $\mathrm{Cx} 43$ is related to an enhanced association of $\mathrm{Cx} 43$ with kinases such as PKC and p38 mitogen-activated protein kinases (MAPK)
[27], while it is independent on the RISK and SAFE pathway [31]. We could show previously that the PKC-MAPK pathway is most likely not involved in the protective effects of RIPC [14]. It therefore remains to be elucidated how RIPC contributes to the preservation of Cx43 phosphorylation on a molecular level.

While most Cx43 molecules are found in the sarcomlemma of cells, $\mathrm{Cx} 43$ is also located in the mitochondrial membrane of mammalian cardiomyocytes $[32,33]$. It has been shown that mitochondrial Cx43 is involved in the events following IPC [32], but there are no data dealing with mitochondrial $\mathrm{Cx} 43$ in the context of RIPC. Our study however focused on sarcolemmal $\mathrm{Cx} 43$ and further studies are necessary to analyze a potential influence of mitochondrial $\mathrm{Cx} 43$ in the context of RIPC.

\section{Conclusion}

In summary, our data show that RIPC has an impact on ischemia-induced $\mathrm{Cx} 43$ dephosphorylation, lateralization and degradation. Further studies are necessary to investigate the exact molecular events leading to the preserved phosphorylation of $\mathrm{Cx} 43$ following RIPC and a potential impact of mitochondrial Cx43.

\section{Additional file}

Additional file 1: Table S1. Hemodynamic variables molecular biology experiments. Table S2. Hemodynamic variables infarct size series.

\section{Abbreviations}

AAR: Area at risk; Cx43: Cx43; IPC: Ischemic preconditioning; I/R: Ischemia and reperfusion; nAAR: Area not at risk; RIPC: Remote ischemic preconditioning.

\section{Competing interests}

The authors declare that they have no competing interests.

\section{Authors' contributions}

TB Study design, molecular biology experiments, manuscript writing; $\mathrm{RH}$ Animal experiments, manuscript revision, AG Molecular Biology experiments, BHP Study design, manuscript revision, VK Confocal Laser Scanning Microscopy FB animal experiments, IB Study design, manuscript revision, $\mathrm{AH}$ Study design, animal experiments, manuscript writing. All authors read and approved the final manuscript.

\section{Acknowledgement}

The excellent technical assistance of Yvonne Grüber, Claudia Dohle and Antje Nebert (Department of Anesthesiology, University Hospital Duesseldorf, Germany) is gratefully acknowledged.

\section{Funding}

This work was supported by a starter grant of the Society of Cardiovascular Anesthesiologists (SCA).

\section{Author details}

${ }^{1}$ Department of Anesthesiology, University Hospital Duesseldorf, Moorenstr. 5, 40225 Düsseldorf, Germany. ${ }^{2}$ Clinic for Gastroenterology, Hepatology and Infectious Diseases, Heinrich-Heine-University, 40225 Düsseldorf, Germany. ${ }^{3}$ Department of Cardiovascular Physiology, Heinrich-Heine-University, 40225 Düsseldorf, Germany. 
Received: 30 April 2014 Accepted: 11 August 2014

Published: 27 August 2014

\section{References}

1. Przyklenk K, Bauer B, Ovize M, Kloner RA, Whittaker P: Regional ischemic 'preconditioning' protects remote virgin myocardium from subsequent sustained coronary occlusion. Circulation 1993, 87:893-899.

2. Kharbanda RK, Mortensen UM, White PA, Kristiansen SB, Schmidt MR, Hoschtitzky JA, Vogel M, Sorensen K, Redington AN, MacAllister R: Transient limb ischemia induces remote ischemic preconditioning in vivo. Circulation 2002, 106:2881-2883.

3. Botker HE, Kharbanda R, Schmidt MR, Bottcher M, Kaltoft AK, Terkelsen CJ, Munk K, Andersen NH, Hansen TM, Trautner S, Lassen JF, Christiansen EH, Krusell LR, Kristensen SD, Thuesen L, Nielsen SS, Rehling M, Sørensen HT, Redington AN, Nielsen TT: Remote ischaemic conditioning before hospital admission, as a complement to angioplasty, and effect on myocardial salvage in patients with acute myocardial infarction: a randomised trial. Lancet 2010, 375:727-734.

4. Thielmann M, Kottenberg E, Kleinbongard P, Wendt D, Gedik N, Pasa S, Price V, Tsagakis K, Neuhauser M, Peters J, Jakob H, Heusch G: Cardioprotective and prognostic effects of remote ischaemic preconditioning in patients undergoing coronary artery bypass surgery: a single-centre randomised, double-blind, controlled trial. Lancet 2013, 382:597-604.

5. Rodriguez-Sinovas A, Boengler K, Cabestrero A, Gres P, Morente M, Ruiz-Meana M, Konietzka I, Miro E, Totzeck A, Heusch G, Schulz R, Garcia-Dorado D: Translocation of connexin 43 to the inner mitochondrial membrane of cardiomyocytes through the heat shock protein 90-dependent TOM pathway and its importance for cardioprotection. Circ Res 2006, 99:93-101.

6. Davis LM, Kanter HL, Beyer EC, Saffitz JE: Distinct gap junction protein phenotypes in cardiac tissues with disparate conduction properties. J Am Coll Cardiol 1994, 24:1124-1132.

7. Schulz R, Heusch G: Connexin 43 and ischemic preconditioning. Cardiovasc Res 2004, 62:335-344.

8. John SA, Kondo R, Wang SY, Goldhaber Jl, Weiss JN: Connexin-43 hemichannels opened by metabolic inhibition. J Biol Chem 1999, 274:236-240.

9. Vetterlein F, Muhlfeld C, Cetegen C, Volkmann R, Schrader C, Hellige G Redistribution of connexin43 in regional acute ischemic myocardium: influence of ischemic preconditioning. Am J Physiol Heart Circ Physiol 2006, 291:H813-H819.

10. Tansey EE, Kwaku KF, Hammer PE, Cowan DB, Federman M, Levitsky S, McCully JD: Reduction and redistribution of gap and adherens junction proteins after ischemia and reperfusion. Ann Thorac Surg 2006, 82:1472-1479.

11. Jain SK, Schuessler RB, Saffitz JE: Mechanisms of delayed electrical uncoupling induced by ischemic preconditioning. Circ Res 2003, 92:1138-1144.

12. Schwanke U, Li X, Schulz R, Heusch G: No ischemic preconditioning in heterozygous connexin 43-deficient mice-a further in vivo study. Basic Res Cardiol 2003, 98:181-182.

13. Schwanke U, Konietzka I, Duschin A, Li X, Schulz R, Heusch G: No ischemic preconditioning in heterozygous connexin43-deficient mice. Am J Physiol Heart Circ Physiol 2002, 283:H1740-H1742.

14. Heinen NM, Putz VE, Gorgens Jl, Huhn R, Gruber Y, Barthuber C, Preckel B, Pannen BH, Bauer I: Cardioprotection by remote ischemic preconditioning exhibits a signaling pattern different from local ischemic preconditioning. Shock 2011, 36:45-53.

15. Heinen A, Huhn R, Smeele KM, Zuurbier CJ, Schlack W, Preckel B, Weber NC, Hollmann MW: Helium-induced preconditioning in young and old rat heart: impact of mitochondrial $\mathrm{Ca}(2+)$-sensitive potassium channel activation. Anesthesiology 2008, 109:830-836.

16. Pfaffl MW: A new mathematical model for relative quantification in real-time RT-PCR. Nucleic Acids Res 2001, 29:e45.

17. Pfaffl MW, Horgan GW, Dempfle L: Relative expression software tool (REST) for group-wise comparison and statistical analysis of relative expression results in real-time PCR. Nucleic Acids Res 2002, 30:e36.

18. Solan JL, Lampe PD: Connexin 43 phosphorylation: structural changes and biological effects. Biochem J 2009, 419:261-272.

19. Brandenburger T, Grievink H, Heinen N, Barthel F, Huhn R, Stachuletz F, Kohns M, Pannen B, Bauer I: Effects of remote ischemic preconditioning and myocardial ischemia on microRNA-1 expression in the rat heart in vivo. Shock 2014 [Epub ahead of print].
20. Hausenloy DJ, Yellon DM: Remote ischaemic preconditioning: underlying mechanisms and clinical application. Cardiovasc Res 2008, 79:377-386.

21. Hausenloy DJ, Yellon DM: Preconditioning and postconditioning: underlying mechanisms and clinical application. Atherosclerosis 2009, 204:334-341.

22. van Veen $T A$, van Rijen HV, Jongsma HJ: Physiology of cardiovascular gap junctions. Adv Cardiol 2006, 42:18-40.

23. Solan JL, Marquez-Rosado L, Sorgen PL, Thornton PJ, Gafken PR, Lampe PD: Phosphorylation at $\mathrm{S} 365$ is a gatekeeper event that changes the structure of Cx43 and prevents down-regulation by PKC. J Cell Biol 2007, 179:1301-1309.

24. Jeyaraman MM, Srisakuldee W, Nickel BE, Kardami E: Connexin43 phosphorylation and cytoprotection in the heart. Biochim Biophys Acta 1818, 2012:2009-2013.

25. Beardslee MA, Lerner DL, Tadros PN, Laing JG, Beyer EC, Yamada KA, Kleber AG, Schuessler RB, Saffitz JE: Dephosphorylation and intracellular redistribution of ventricular connexin 43 during electrical uncoupling induced by ischemia. Circ Res 2000, 87:656-662.

26. Huang XD, Sandusky GE, Zipes DP: Heterogeneous loss of connexin43 protein in ischemic dog hearts. J Cardiovasc Electrophysiol 1999, 10:79-91.

27. Schulz R, Gres P, Skyschally A, Duschin A, Belosjorow S, Konietzka I, Heusch G: Ischemic preconditioning preserves connexin 43 phosphorylation during sustained ischemia in pig hearts in vivo. Faseb J 2003, 17:1355-1357.

28. Garcia-Dorado D, Inserte J, Ruiz-Meana M, Gonzalez MA, Solares J, Julia M, Barrabes JA, Soler-Soler J: Gap junction uncoupler heptanol prevents cell-to-cell progression of hypercontracture and limits necrosis during myocardial reperfusion. Circulation 1997, 96:3579-3586.

29. Azzam El, de Toledo SM, Little JB: Direct evidence for the participation of gap junction-mediated intercellular communication in the transmission of damage signals from alpha -particle irradiated to nonirradiated cells. Proc Natl Acad Sci U S A 2001, 98:473-478.

30. Zeevi-Levin N, Barac YD, Reisner Y, Reiter I, Yaniv G, Meiry G, Abassi Z, Kostin S, Schaper J, Rosen MR, Resnick N, Binah O: Gap junctional remodeling by hypoxia in cultured neonatal rat ventricular myocytes. Cardiovasc Res 2005, 66:64-73.

31. Sanchez JA, Rodriguez-Sinovas A, Barba I, Miro-Casas E, Fernandez-Sanz C, Ruiz-Meana M, Alburquerque-Bejar JJ, Garcia-Dorado D: Activation of RISK and SAFE pathways is not involved in the effects of $\mathrm{Cx} 43$ deficiency on tolerance to ischemia-reperfusion injury and preconditioning protection. Basic Res Cardiol 2013, 108:351.

32. Boengler K, Dodoni G, Rodriguez-Sinovas A, Cabestrero A, Ruiz-Meana M, Gres P, Konietzka I, Lopez-Iglesias C, Garcia-Dorado D, Di Lisa F, Heusch G, Schulz R: Connexin 43 in cardiomyocyte mitochondria and its increase by ischemic preconditioning. Cardiovasc Res 2005, 67:234-244.

33. Ruiz-Meana M, Nunez E, Miro-Casas E, Martinez-Acedo P, Barba I, Rodriguez-Sinovas A, Inserte J, Fernandez-Sanz C, Hernando V, Vazquez J, Garcia-Dorado D: Ischemic preconditioning protects cardiomyocyte mitochondria through mechanisms independent of cytosol. J Mol Cell Cardiol 2014, 68:79-88

\section{doi:10.1186/s12967-014-0228-8}

Cite this article as: Brandenburger et al:: Remote ischemic preconditioning preserves Connexin 43 phosphorylation in the rat heart in vivo. Journal of Translational Medicine 2014 12:228.

\section{Submit your next manuscript to BioMed Central and take full advantage of:}

- Convenient online submission

- Thorough peer review

- No space constraints or color figure charges

- Immediate publication on acceptance

- Inclusion in PubMed, CAS, Scopus and Google Scholar

- Research which is freely available for redistribution 